\title{
Is there an ethical role for the history of design? Redeeming through history the possibility of a humane world
}

What follows is not the abstract or even the basis of the talk that I will give in Aveiro so much as a sketching out, in the form of an extended working paper, of the ethical basis from which I would like to try to think about the meaning of doing and thinking about the history of design today. The talk itself will try to ground these abstractions in some concrete exemplars. But in the light of where we are in the world today, a preliminary understanding the ethical and political position of doing work in design, whether as history or practice (and these two things should not be separated) is essential. Such an understanding cannot not but be also philosophical, all the more so that the prime requirement here is to think the linkage between the characteristics and capabilities of design and the possibility of redeeming the world in a humane direction: a project now essential to the question of how this century is survivable without human and ecological catastrophe.

\section{Part I}

'The task to be accomplished is not the conservation of the past, but the redemption of the hopes contained in it.' This injunction, which comes from the introduction to Theodor Adorno and Max Horkheimer's Dialectic of Enlightenment', succinctly defines, for our time, the primary task of historical work. Today, the job is not exposé, in the manner of 40 years ago, when the past was mined ideologically for its complicity in serving power, nor is it "making the case" for (professional) design in the way that, from Pevsner through to

'In English translation, Verso, London, 1979: originally published in New York in 1944. See p. xv 
early design history, was thought to be the major job of writers on design. As the last few years should have made abundantly clear, today we are in a very different world indeed. The complacencies (as well as the hopes) of the modern era have vanished. Economically, we are no longer "in" industrialization, which means we are no longer in the world in which the particular nature of the industrial technology and the forms of economy that emerged across the C19th and C2oth demanded design in the particular forms we still know it by. Even if these forms still echo in our culture, particularly institutionally (-as ever the 'superstructure' lags behind the 'base') ours is essentially, which means structurally a very different world.

The economic, but not only economic, implications of the shift from industrial to financial capitalism² - few of which appear to be beneficial for the majority, and many of which are deeply inimical to overall well-being-are what we will have to contend with across the next decades. Almost none of these implications objectively lend themselves to the creation of a more humane word. Indeed the opposite appears to be the case. A paradox of our current history-yet it is only apparently a paradox-is thus that today we find ourselves in a world in some ways closer to that which Adorno and Horkheimer wrote out of than at any time since Dialectic of Enlightenment was drafted. In the preface they write of drafting that text 'when the end of Nazi terror was already in sight.' Today, 70 years later, we are witnessing a rise of social attitudes and political parties which, if not yet pointing to the levels of the that terror, give the lie to any notions of Europe and the West as a whole as somehow a haven of intrinsically "civilized" attitudes. The return to levels of inequality not seen since before WWI, especially in the Anglo-Saxon countries but more generally as a world-wide phenomenon, not only feeds these attitudes but points as well to the increasing fragility of the social and political compacts that hold together (but only just) the modern nation state. Underneath both developments, as we know, is the still greater violence of a global economic system that is all too evidently set on course towards ecological and social catastrophe. Taken together these trajectories demand the urgent recovery of all of that is capable of at once acting as a resource against this tendency and of helping us build bridges to a putative better world.

In this context we might think that Europe-the source, after all, of most the world's barbarity over the last 100 years - would feel a special responsibility (in this year of all years) towards the ease with which from what was the day before the 'height of civilization' there can be created a hell on earth. From August 1914 after all the catastrophe of Europe's violent century begins. ${ }^{3}$

But no such responsibility is evident-and not only (if majorly) from Europe's leaders. Illusions fostered by the apparently inexhaustible richness of consumption still succeed in inducing a wholesale focus on the moment that is inimical to serious reflection

${ }^{2}$ Of course accumulation through consumption and through that accumulation through manufacture is still significant, especially today in China. But it is no longer formative. The brutal underlying economic fact is that the direct management and manipulation of capital now offers a rate of return significantly higher than the overall rate of growth of the global economy.

3I should say that, from August 1914 begins Europe's internal violence. In the more than two centuries before Europe had already, and increasingly, exported violence across the world, most savagely, latterly to Africa. 
and to the formation of policies and initiatives remotely adequate to dealing with the scale of threats we face. Self-induced blindness to what is socially developing extends into every professional field. Design does not escape this charge. Its defenses, now as always, are two-fold: that it is inhabits its own field, distinct even from the economy on which it is generally dependent and which it serves; and that it is in any case inherently virtuous. The quantum of truth that both these contain obscures the fact that neither can be simply maintained.

For the first, the illusions of an absolute distinction in practice induced by intellectual and professional divisions of labour do not withstand scrutiny. Fragmentation and specialization of practice and thought is not a 'natural' product of logic but of economic relations ${ }^{4}$. Design (in the capitalized sense of the word) after all owes its professional and modern phenomenal existence to economics. Its relative autonomy is as planned and secured as any other moment of the processes of production and consumption. Moreover, reactive to the core, design autonomy takes its cue from, and is obedient to, what determines it in subaltern position: it self reduces the practices of design to what, at any moment, dominant interests require of them. ${ }^{5}$

In any case, and today perhaps more importantly, the substantive content of what design "does" and what it "knows," is as much obscured as it is clarified by focusing on its autonomy. What the defense of design as an activity unto itself misses is the question of how the practices and capabilities of design tie into the larger human sphere. Particularly as we look towards the future, which means as we look to the possibility of a future, that is a non-catastrophic future, this is crucial. Design has little meaning if it cannot be linked directly to the wider human project. Thought only professionally, design and its history are of little account. . To put it bluntly, neither matter-which precisely explains why, up to the present, for other academic disciplines, design has not been a matter of concern.

From the side of the history of design narrowly conceived one proof of this is the manner in which design research-as well as most practice-ignores this history. Being unable to see in it any real contribution to knowledge, research sidesteps it, and thinks itself all the more scientific for so doing. Design research is of course as mistaken in this as it is in most other aspects of how it conjugates knowledge. It is precisely the almost complete lack of historical perspective in design research that renders what it produces all but null-and-void as genuine understanding. ${ }^{6}$ The visible testament of this is the depressing weakness of most doctorates in design. Yet the stance is understandable,

\footnotetext{
${ }_{4}^{4}$ See the pages Georg Lukács devotes to this topic as a phenomenon of industrial society in History and Class Consciousness (London, Merlin Press, 1971 (orig. 1923)) especially p. 102-107.

${ }^{5}$ The proof of design's real lack of autonomy is that at this moment it is scarcely capable, except at very small scale, of taking a pro-active, or even a critical, stance towards what determines it.

${ }^{6}$ There is an interesting parallel here with economics. In the wake of the profession's embarrassment following the failure to foresee the financial crisis of 2008-9 one contributing factor in terms of the education of the current generation has been thought to be was the large-scale abandonment, from the 1970 s onwards of teaching of the history of economic thought. In so far as the latter at least offered some alternate perspectives and conceptual maps of economic activity it allowed for a richer conceptual mix within the field and did not allow one economic model ('equilibrium theory') to gain unchallenged orthodoxy. Design research today is in the conditions of economics pre-2008.
} 
if not defensible. If, on the grounds of 'discipline,' a field eschews both practice and knowledge and if we have a structural gap between a the norms of putative field and its substantive content, then it is difficult to see in what way that discipline contributes to knowledge.

In a parallel case (that of "political philosophy") the philosopher Alain Badiou used a trenchant rhetorical formulation to lay out the issues involved. The similarities are sufficient for it to throw light on what is involved today in how we think designtheoretically as well as historically.

Pointing out that in how the field presented itself what was clear was not what that field was but only what it was not -'neither the name of a thought... nor the name of an action'-Badiou continued: 'I admit to being quite struck by this double negation. If [it] is not a truth procedure touching the being of the collective in question, or even the construction and animation of a new and singular [praxis], aiming for the... transformation of what is, what can it be?... Neither a determinate factor as far as the objectivity of situations is concerned nor a militant agent in the seizure of their latent possibilities, what does [it] consist in?' ... 'One will demand to know at once if [this activity] must therefore be established on the side of inactive judgment, or of the judgment which issues no maxims for action. ${ }^{7}$

These negations are powerful-precisely for their negative consequences for thought.

'Neither the name of a thought.. nor the name of an action' reduces design essentially to a value, but a value that is not principally inscribed in thought (at the level of a truth procedure) or action (a new and singular transformative praxis) or in the contexts in which it acts ('not a determinate factor ... in the objectivity of situations ... and the seizure of their latent possibilities'). Design is a value exemplified in designed things but there is no understanding of how that value is inscribed, just as everything that is not "value" (thought, action, situation) disappears from explicit consideration. This explains why the history of design-and through it the theories of design that as axioms rule 'commonsense' views as to what design "is"-_are so ambiguous as to its subject matter. It touches upon thought, action, contexts but does grasp any of these fully. ${ }^{8}$ In compensation history turns to judgment and 'facts' (which may not-and usually does not-mean analysis). ${ }^{9}$

But these negations are by no means confined to history. They enter into practice too. Taken together they empty design of its most vital content. Their reconstruction would be at the heart of a renewed understanding of what design as a mode of acting in the world actually achieves. Still, the major problem here, however, does

${ }_{7}^{7}$ The original is from Alain Badiou, Metapolitics (London, Verso, 2005) p. 11, 12, 16. "See my "The Question of Agency in the Understanding of Design," Journal of Design History, Volume 26, Issue 3, August, 2013, p. 331-337

9 But its exact opposite: history as a means of keeping 'the Real at arms length indefinitely' (Badiou, ibid. p. 10) where judgment and assertion postpone the encounter with the complexity of the thing. In such history (and in the practice that unconsciously takes its axioms from history) it is not a 'question of laying down maxims for action, or of analyzing objective configurations,' rather history is to be found principally in 'the judgment that states whether this-which is not an object but an appearing, a taking placepleases me or displeases me, and is exercised in the debate of such judgments' (Badiou, ibid, p. 16). 
not lie principally with history but rather with our conception of the activity, i.e., with our understanding of design.

Professionalization extracts a price that all professions are subject too, once constituted, their quasi-autonomy causes them to lose sight of their ontological role. One thinks here of Adorno's comment on applied thought-that it suffer(s) 'what triumphant thought has always suffered. [If] it willingly emerges from its critical element to become a mere means at the disposal of an existing order, then despite itself it tends to convert the positive it elected to defend into something negative and destructive. ${ }^{10}$ Rendered instrumental, all that is most valuable in the activity gets lost to sight. Thus, for example, while design still wishes to believe it is a force for good, in fact, beyond self-congratulation, it continues to finds it hard-indeed all but impossible - to explain in what ways it is indeed "good." A by no means negligible consequence of this is that it vitiates all claims to virtue." Stripped of substantive content assertions of the inherent virtues of design lose credibility. But as the virtues of design disappear and design itself stands for a process often seen as at once banal (in its applicability) ${ }^{12}$ yet still mysterious (in its transactions, in its mode of operation) the term loses resonance.

What adds to the confusion is that today design seemingly has no limit to what it may be applied to, either in extent (-'ever larger assemblages of production'-) ${ }^{13}$ or to what it may contain or 'comprehend.' As useful instance of this last point note Latour's observation that 'everyone with an iPhone knows that it would be absurd to distinguish what has been designed from what has been planned, calculated, arrayed, arranged, packed, packaged, defined, projected, tinkered, written down in code, disposed of and so on. From now on, "to design" could mean equally any or all of those verbs."14

Unsurprisingly, the sense today that the word is all but emptied of meaning is common even within design. The recent fate of the term "design thinking"-which has rapidly shown itself to be neither a "thinking" nor particularly useful for designing-

\footnotetext{
${ }^{10}$ Dialectic of Enlightenment, ibid, p. xii.

${ }^{11}$ Let us be clear: design possesses virtues. There would be no point in pursuing the activity if it did not. The designer Gui Bonsiepe spoke beautifully on this issue a few years ago--see the short essay, 'Some Virtues of Design' prepared as a contribution to the symposium "Design beyond Design..." in honor of Jan van Toorn, held at the Jan van Eyck Academy, Maastricht, November 1997. The point is not that there are not virtues in design, the question is how they are understood, articulated and brought to consciousness both is thought and through practice.

12 Latour's damning comment: 'A surface feature in the hands of a not-so-serious profession that added features in the purview of much more serious professionals (engineers, scientists, accountants). See "A Cautious Prometheus? A Few Steps towards a Philosophy of Design": a lecture given to the Networks of Design meeting of the Design History Society, Falmouth, Cornwall, 2008.

${ }^{13}$ Latour again: the opening paragraph of the above lecture: "It came to me at a launching party for a Networks of Design meeting - I was struggling to grasp the extent to which the word "design" has been expanded when we were invited to visit an exhibition called "Re-imagining Cornwall"! I was aware that corporations had to be reengineered, natural ecosystems reclaimed, that cities had to be remodeled and wastelands redeveloped. I knew that neighborhoods had to be beautified and political platforms scripted, and that interiors had to be redecorated and journal layouts restyled. The Cornwall exhibit confirmed that I was indeed on the right track: if entire provinces can be redesigned then the term no longer has any limit:'

${ }^{14}$ Latour ibid.
} 
perfectly illustrates the processes at work here. One result is that the more design seeks to assert its structural (economic, social, moral) necessity, the more the gap between the assertion and the substantive understanding that underpins it becomes glaringly apparent.

These confusions have implications at the levels of practice. One result is that business and social innovation begin to think "design" in their own terms and distinct from the discourse (such that it is) around design as most in this hall think it. But these confusions also reach into and make difficult the depth understanding of what design comprehends itself as achieving.

Thus the intuition that design (in the words of the late historian and economist of design John Heskett) ${ }^{15}$ is at once that which enables us

(i) 'to create a world of artifice to meet our needs and give meaning to our lives,' and

(ii) 'to beneficially reshape the world of artifice we have created and inhabit'; while design

(iii) is, itself, at its deepest, 'a unique characteristic of what defines us as human beings on a par with literature and music'

is both accurate in essence thought yet remains a mere hope or aspiration (only "accidentally" realized) in so far as these capabilities and characteristics cannot be articulated, and not only in proto-professional but also in ontological terms.

But it is not only understanding that is thereby hobbled. A weakened understanding of design cannot guide practice-which is precisely why so much professional design today offers a mere shadow of its sometime aspiration. Design that has lost access to its ontological moments loses access to its own practice-which, as we know, is then all too vulnerable in the face of dominant instrumental pressures. ${ }^{16}$ One outcome is trivialization. Another is the ease with which design evacuates responsibility for its actions. There is little need to detail this. Daily practice all too often confirms both in the worst possible way. ${ }^{17}$

${ }^{15}$ British design historian who died in 2014. Author of Industrial Design, German Design 1870-1918, Design: A Very Short Introduction and an important series of works on the economic value of design. ${ }^{16}$ The weekend I was sketching these notes an article indicative of this condition appeared in the Financial Times. Entitled, 'The End of Architecture' their architecture critic Edwin Heathcote points to the enfeeblement of architects: 'their role is now principally as shape makers, sculpting profiles for developers' logos. They work for contractors, way down the construction food chain, and have been complicit in their own decline ... all that is are the handful of boutique projects that serve to assure that there is some rationale behind those years of education and those centuries of culture.' Financial Times, May 31/June 1, 2014

${ }^{17}$ As the Dutch graphic designer Jan van Toorn has incisively noted, the 'coinciding group interests of clients and the [design] disciplines' has meant that the 'practices and notions of [professional] design have been introduced into society on an ever larger scale. This has... fostered the acceptance of the images and doctrines of design, ... [and] strengthened the position of design in relation to economic, social and political intercourse' (van Toorn 1994: 150). But what suffers in this process is the relation to those whom, ostensibly, design serves. While design still wishes to 'claim responsibility for the interests of users,' and presents its 'professional and private concerns as a public interest,' 'under the pressure of neo-liberalism and the power relationships of the free market,' design has been 'forced to dilute the public wine with a large dose of private water.' In this process not only is the designer's individual freedom, ostensibly still existing within a space of its own, infiltrated by the client's way of thinking, but design ends up discovering that, for all its attempted accommodation with these interests, it has become little more than a handmaiden to market concerns. Small wonder then (as van Toorn puts it in 
This is precisely however, why today the injunction that 'the task to be accomplished is not the conservation of the past, but the redemption the hopes contained in it,' could not, for design, be more acute or significant. To redeem the hopes contained in the [designed] past is to recover the deeper contents contained in the assumption of design's virtue. It is only when design sees itself as engaging with human hopes and aspirations in the wide sense-and can articulate the nature of that engagement; can explain in what way it engages and helps materialize those hopes-that it can come back to visibility (to itself as well as to others) as no longer the embarrassment that, in practice, if not in its self-image, it so often exemplifies.

On the other side, that of the social, or of history, the requirement is equally as strong.

Faced with crisis, and today we are in crisis-it is now and for the foreseeable future our inescapable condition, ecologically certainly, social, politically and economically too ${ }^{18}$-one demand irrevocably placed on our agenda is that we develop capacities to engage with the world otherwise than we are now doing.

Both of these aspirations-towards the recovery of design and towards the recovery of the hopes embodied in the past towards a humane future-are future oriented. Yet both are dependent upon recouping the past. The latter is not 'dead,' not the museum, not "merely" history, but the site of the possible redemption of the futurenow-lost. The term means that, for the first time in human history, the future is today what cannot, as a generality, any longer be assumed, least of all as that which is 'naturally' improved from the present. ${ }^{19}$ That which once naturally indicated hope-because it incarnated possibility, and in the modern period was the very source of energies for transforming the present-is today a zone of anxiety and uncertainty. (Bruno Latour offers a neat formulation of where we have got to when he notes that 'ecological crises, in such a view, are the slow and painful realization that there is no outside anymore. It means that none of the elements necessary to support life can be taken for granted').

for [missing] essential forms of social communication' - whilst at worst, 'drawing on its roles in the organization of production and in helping to stimulate consumption', it is at once hand-in-glove with the intensifying creation of a fundamentally unsustainable world (a role it is incapable of acknowledging with any honesty) and part of the 'extensive disciplining of the general public' in the terms of the market - a disciplining 'whose most far-reaching consequence is ... a political neutralization that is at odds with the functioning of an open and democratic society'. See the essays 'Rethinking the Visual: Essayistic Fragments on Communicative Action', in Ole Bouman (ed.) And Justice for all, Maastricht: Jan van Eyck Akadmie (1994); and 'Communication Design: a Social Practice' in Jan van Toorn (ed.) Design beyond Design, Maastricht: Jan van Eyck Akadmie (1997).

${ }^{18}$ We are faced with a permanent future world crisis because the move to a world in which the artificial and not nature is now the prime horizon, medium and condition of existence is irrevocable. This means that unsustainment is a continuing possibility for every future to society to come. We have reached a historical point where we have no escape from the possibility of 'de-futuring' and this would be true even if we achieved, in some locations, in some places, a "sustainable" economy. On thinking "crises" beyond the concept of crisis, see Janet Roitman, Anti-Crisis (Durham, Duke University Press, 2014). I Some of these points are dealt with in more depth in the essays in Clive Dilnot, Tony Fry and Susan Stewart, Design and the Question of History (London, Bloomsbury, 2014, forthcoming).

19 We are certainly not assured of the future as in any sense "progress" on what we have now, if by progress we mean here development towards a more humane, equal and sane world. The term means also that we are in danger of losing hope in the future except as the extrapolation of what-is. 
As we ponder this we realize that there is an almost exact relation between the loss the future and our loss of the past..$^{\circ}$ One reason for this is that while the crisis of the future is objective we experience it as a loss to thought. We discover that we cannot bring the future into focus as a zone of possibility except as the technological and economic extrapolation of what-is, or as an inchoate fear of social crises that we cannot even name with any precision. On either side this forbids real consideration of alternatives, of what could-be-meaning what could be qualitatively other, what could, or what might, be instituted to both stave-off possible catastrophe and to build those social and futural bridges which might reach across to a humane and more pacified world.

In relation to this project design recoups its history as hope in the interests of a future that cannot any longer be assumed but must rather be brought carefully into being. This means that recovery of the past is the condition for the recovery of the future. ${ }^{21}$ But as we re-cover for the sake of the future we recover from it lessons we can take into the task of reconfiguring what-is in the interests of the future.

Design is key to this process, not as "Design," thought only as a marginal profession, but as, and because, as will come clear below, design considered as a mode of acting in the world is a crucial element in shepherding the future into being. Design is in this sense perhaps-and I stress perhaps, no absolute assumptions should at this stage be made, the possibility remains yet a question-one of the vital agencies and capacities, one of the models of acting (as a 'cautious Prometheus' in Latour's at first odd-sounding but by no means foolish phrase) through which, in contradistinction to the "Promethean" forms of the technology and economy as we now know them, we can work towards the recouping of the future.

But (to repeat the sentence made above) to redeem the hopes contained in the [designed] past is also to recover the deeper contents contained in the perceptions of design's virtue. If it is only 'when design sees itself as engaging with human hopes and aspirations in the wide sense-and can articulate the nature of that engagement, can explain in what way it engages and helps materialize those hopes-that it can come to full visibility (to itself as well as to others)' then the project of redeeming the future through redeeming the hopes of the past, and redeeming design, are one and the same. In this project design recoups its history as the self-understanding of what in fact, thought now as a generalized capability and capacity (though never autonomously) it can concretely achieve.

But that design might be anything more, in the future, than 'a surface feature in the hands of a not-so-serious profession,' is also down to the third aspect of this equation,

${ }^{20}$ On 'de-futuring' see the recent trilogy of books by Tony Fry, Design Futuring; Design as Politics; Becoming Human by Design (London, Bloomsbury, 2009, 2011, 2012).

${ }^{21} A l l$ history is of course written with an eye to the future. But today the emphasis called for is new; the change can be seen by considering a famous line from Walter Benjamin. In 1940, in one of the "Theses on the Philosophy of History" Benjamin wrote that only those historians who are 'convinced ... that not even the dead will be safe from the enemy if he is victorious' would have 'the gift of setting alight the sparks of hope in the past.' In the light of what is emerging we might re-write this line to lay emphasis not only on the necessity of "saving" the dead but the unborn. It is today their possibility that we need to 
the fact that we are in the process of a very deep historical shift. For design, the epoch in which it could act "sufficiently well" without knowing what it was doing 22 or without articulating, better than it has so far managed, its genuine capabilities (and thus also its limits) is essentially over. It is over because, to take up directly now one of the themes of this conference-though it has been implicit all along-what we are dealing with here is transition: the transition not just from design in the industrial epoch to design in the epoch of the artificial, but from the industrial epoch per se to the epoch of the artificial per se. By 'epoch of the artificial' I mean that we are now entering into (have being doing so at increasing pace since c. 1945) an epoch in which it is the artificial and not nature that is now the horizon, medium and prime condition, of our global existence. The industrial epoch initiated industrialization and artifice at global scale. But even as late as 1939 this did not constitute the totality of the world. After 1945, the A-bomb symbolically (as destructive capacity) and the spread of industrial culture and capitalist consumption substantively (to say nothing of the mechanization of agriculture, urbanization and, after 1990, both ubiquitous digitalization and increasing evidence of man-made climate change) set in chain a transition that is still on-going but whose outlines are now clearly perceptible, where indeed the horizons, medium and prime conditions of existence are now set by and through the artificial.

As will become clear below, what changes in this transition is structural position of design within the overall ambience of the world-as-artificial. From a subaltern position as an essential, but still marginal, aspect of industrial production and consumption, design today emerges-though not necessarily as "Design"23 —as a becoming-ubiquitous mode of acting in the world.

What does not change however, or what changes less than we might imagine, is that design in this new sense does not simply appear as if without precedent or without context; rather, and this is what gives history today its potential force, many, perhaps in one form or another all, of the moments and aspects of design as a mode of acting in the world-design 'in the expanded field' we could say-find their anticipation in history. History then in this sense becomes a means of charting-expanding, making adequatethe understanding of design; it is the recouping of what design "is" (and might be) as we enter into this epochal transition (and which is certainly, at minimum, a transition out of the structures and norms of the older industrial economy).

\footnotetext{
22 'Although I designed hundreds of successful products for major corporations, it suddenly occurred to me that I didn't understand what I had been doing...'-- the US designer Jay Doblin in an interview from 1980.

${ }^{23}$ To see design beyond "Design" is one of the intellectual challenges of now.
} 


\section{Part II}

But how, in practical terms, can this be achieved? And in what ways, precisely is design recuperative in the sense implied here? One very broad answer, though it is less directly an answer than a framework for thinking about the relation past-future, is that, as Latour puts it in a way that is at once naive and profound [in the paper l've already referred to, i.e., the paper he offered to the Design History Society in the UK in 2009] the expansion of design is a symptom at once of this transition and of a deep 'change in the ways in which we deal with objects and action more generally.24

In other words, in the transitions we are now going through not only do 'industry' and 'economy' shift their character and their role (the former no longer formative in the same way; the latter shifting its arenas of value-creation) but at a deeper level so too does the nature, character and work of objects, and so too the nature, character and work of action. For the first, objects (or perhaps better, products) function, in Latour's terminology as "things," i.e., they become increasingly conceivable as 'projects,' complex and 'disputed' 'assemblages of contradictory issues.'

For the second, we experience of what Latour calls a 'sea-change in our collective definition of action,' a movement towards a non- or a post-Promethean sense of what it means to act.' 'At the very moment when the scale of what has to be re-made has become infinitely larger-no political revolutionary committed to challenging capitalist modes of production has ever considered re-designing the earth's climate-what it means to make something is also being deeply modified.

But above all, says Latour, what we see in what is emerging today, and what unites these two movements, is that what were previously "matters of fact" now ... become "matters of concern."

What does Latour mean by all this? How do we understand it and its implications both for practice and history?

One point is that these developments, and which of course run sharply against the grain of earlier modern technologically-based conceptions of objects and action, are for Latour not merely technical, or superficial changes in the form of things. They are nothing less, in fact, than an indication of 'a deep shift in our emotional make-up.' What is the basis of this shift? Objectively, as already hinted, it is the rise of the artificial and of artificiality per se-to the point where the question of the artificial is the question with which we must deal. ${ }^{25}$ But the subjective basis of this move is subtly different. It is, suggests Latour, a different understanding of dependency, a profoundly "anti-modernist" understanding. 'A modernist' says Latour, 'is someone who lives under a vast dome, and

${ }^{24}$ Latour, ibid. In referring extensively to this paper below I shall not further cite it. The paper is available on-line at http://www.bruno-latour.fr/sites/default/files/112-DESIGN-CORNWALL-GB.pdf. ${ }^{25} \mathrm{Cf}$. Latour: 'Yes humans have to be artificially made and remade, but everything depends on what you mean by artificial and even more deeply by what you mean by "making." ' 
who sees things as though sitting under a huge architecture, the Globe of Science, the globe of Reason, the globe of Politics. For the modernist, the humanist is the one who reads a book under a lamp or who sits clothed in some sort of Roman toga on the stairs of a huge amphitheater under the painted fresco of some immense dome... except that in the modernist architecture, the life supports necessary for this Dome or this Globe to be sustainable have not been explicated. A modernist takes for granted that there will always be air, space, water, heat, for the development of his or her "global view." But of course this is precisely what today cannot be assumed, and in fact never could. Athens depended on the energy of slaves ("speaking objects": Aristotle). As conditions are now forcing us to recognize, 'to define humans is to define the envelopes, the life support systems, the Umwelt that make it possible for them to breathe. This is exactly what humanism has always missed.' The dissociated subject is a fiction. In fact we are always 'dependently enveloped, entangled, surrounded; we are never outside without having recreated another more artificial, more fragile, more engineered envelope. We move from envelopes to envelopes.'

Latour's analogy is the cosmonaut. 'To try to philosophize about what it is to be "thrown into the world" without defining more precisely, more literally ... the sort of envelopes into which humans are thrown, would be like trying to kick a cosmonaut into outer space without a spacesuit.' He continues the analogy further, which gives us the sense of what is now changing, and anticipates a crucial concept to come: 'When you check on your space suit before getting out of the space shuttle, you are radically cautious and cautiously radical... you are painfully aware of how precarious you are, and yet simultaneously, you are completely ready to artificially engineer and to design in obsessive detail what is necessary to survive ... the cosmonaut is emancipated from gravity because he or she never lives one fraction of a second outside of his or her life supports. To be emancipated and to be attached are two incarnations of the same event, provided you draw your attention to how artificial atmospheres are well or badly designed' - and providing that you accept, in the first place, this dependency, a dependency of course enforced on the cosmonaut and now (in effect) forced on us by incipient ecological disaster. The 'emotional shift' is therefore this: it the (often reluctant!) admission that things-objects-matter. Latour again: ... when humanists accuse people of "treating humans like objects," they are thoroughly unaware that they are treating objects unfairly. A humanist cannot imagine that objects may be things, that matters of facts might be matters of concern, that the whole language of science and engineering might be portrayed as anything other than the boring carriers of the indisputable necessities that modernism has rendered popular. Humanists are concerned only about humans; the rest, for them, is mere materiality or cold objectivity.' But in a condition of dependency, and not just on nature but also on artifice, this stance cannot hold.

Both humans and non-humans have today been treated as "matters of grave and careful concerns." Our period is the struggle to come to terms with this new objective and subjective reality. ${ }^{26}$

Both humans and non-humans have today been treated as "matters of grave and careful concerns." Our period is the struggle to come to terms with this new objective and subjective reality. 
The first, already in effect noted, is the idea that 'the more objects are turned into things-that is the more matters of fact are turned into matters of concern-the more they are rendered into objects of design through and through.' Concern means dispute: incommensurable world-views. Action therefore becomes necessarily a matter of negotiating incommensurability. Design, which in its essence is the negotiation of incommensurability therefore becomes ubiquitous in making; or, to put it another way, today making "becomes" design-if in complex ways where, as in the instance of i-phone earlier, design becomes extended considerably beyond that which we traditionally thought. A paradox immediately apparent here is that while the development from 'matters of fact' to 'matters of concern' may indeed mark the transition we are now going through, it also marks a return to older models of making. The concept of a 'matter of fact' can scarcely enter pre-modern thought. To put this the other way around, before industrialization almost no objects were simply 'matters of fact.' During industrialization the object in many ways becomes reduced to a statement of fact. It is determined by law and hence has the status of an apparent "fact." ${ }^{27}$ The return to objects as "things," 'matters of concern' in Latour's vocabulary; complex gatherings and assemblages of disputed and contradictory issues-objectively calls forth design, not as the subjective balm for objective law (designing as packaging) but as the deeper level process of configuratively "resolving" incommensurable moments and demands. 'The idiom of matters of concern reclaims matter, matters and materiality and renders them into something that can and must be carefully redesigned.' Design, in this view, is the name we give to that mode of configurative acting that is capable of, this task. ${ }^{28}$

The second proposition echoes the first by emphasizing the manner in which today 'matter is absorbed into meaning (or rather as contested meaning) in a more and more intimate fashion.' As things, Latour says, are increasingly 'conceivable as complex assemblages of contradictory issues,' so the question of artefactual depth comes to the fore. It is no longer (not that it ever truly was) a case of design only adding 'superficial meaning to what was brute matter and efficiency' ('a veneer of form') it is that the thing itself (and thing here is tangible or intangible, object, interaction or situation) is both the result of, and itself embodies, knowledge as well as the results of and capabilities of, interpretation. It thus in turn requires 'all of the tools, skills and crafts of interpretation

\footnotetext{
${ }^{26}$ Nothing much is left of the scenography of the modernist theory of action: no male hubris, no mastery, no appeal to the outside, no dream of expatriation in an outside space which would not require any life support of any sort, no nature, no grand gesture of radical departure - and yet still the necessity of redoing everything once again in a strange combination of conservation and innovation that is unprecedented in the short history of modernism.

${ }^{27}$ See Herbert Simon, Sciences of the Artificial, ibid, p. 113.

${ }^{28}$ Latour's instance comes design as a mode of acting vis-à-vis reconciling the "impossibilities" of ecological politics. How can we draw together matters of concern so as to offer to political disputes an overview, or at least a view, of the difficulties that will entangle us every time we must modify the practical details of our material existence? We know that whenever we prepare to change our fixtures from incandescent to low energy light bulbs, to pay our carbon expenses, to introduce wind farms, to reintroduce the wolf to the Alps, or to develop corn based fuel, immediately, some controversy will be ignited that turns our best intentions into hell. And we are no longer able to stop the controversies by stating the undisputable facts of the matter because facts are constantly disputed.
} 
to [be brought] to the analysis of that thing.' Adequate method is no longer only description. A hermeneutic is also required. Matter absorbed into meaning-which also means meaning materialized or embodied in matter-is of course the inter-relation of mind and matter. This also means that things thought in this perspective stand as the immediate refutation of that concept which has most painfully dogged attempts to think things since Kant, the distinction between 'means' and 'ends.' Ever false, the digital, the folding together of language (code) and instrumentality, is the final nail in the coffin of this opposition. In truth it was ever false, a poor rationalization of a felt necessity to justify the distinction of fine art-and a displacement from a more authentic thinking concerning things, their work and their configuration, and their poetics. ${ }^{29}$

The third proposition that underpins Latour's paradigm shift is that in so far as making extends into design then it 'necessarily involves an ethical dimension': 'The spread of design to the inner definition of things carries with it not only meaning and hermeneutics, but also morality. More exactly it is as if materiality and morality where finally coalescing' [my emphasis]. Latour is emphatic on this point. 'By expanding design so that it is relevant everywhere designers [necessarily] take up the mantle of morality as well.' He continues: 'This is of great importance because if you begin to redesign cities, landscapes, natural parks, societies, as well as genes, brains and chips, no designer will be allowed to hide behind the old protection of matters of fact. No designer will be able to claim "I am just stating what exists" or "I am simply drawing the consequences of the laws of nature," or "l am simply reading the bottom line." This in turn extends and returns questions of making and design to politics-and specifically the politics of what Latour calls, 'matters of concern.' 'A politics of matters of facts and of objects has always seemed far-fetched; a politics of designed things and issues is somewhat more obvious' -and is for us only in any case the manifestation of a concrete problem: 'What is clear is that the collective definition of what artificial life supports are supposed to be [today] becomes the key site of politically minded investigation.' Designing is here one of the ways of thinking and acting (thinking for acting) around and in address to this problem.

These three propositions are for Latour the equivalent to concrete truths. That today matters of fact are becoming 'matters of concern' (and hence of design); that we are in a time of the interpenetration of mind and matter (the 'absorption of matter into meaning') and that today making 'necessarily involves the ethical' (and by natural extension the political) are the truths of our moment. They are the conditions that underpin what he calls the 'five advantages of the concept of "design"' for our moment.

By "advantages" he means first advantages in opposition to, or vis-à-vis or as an alternative to what-is, i.e., existing, "modern" means of technological and (although he fastidiously hardly refers to the term) capitalist modes of collective action. But, second, he also means this term affirmatively, in terms of how the mode of generalized acting we can call design resonates, even if in some ways seemingly paradoxically, vis-à-vis what is now emerging as the new conditions, possibilities and demands of making.

${ }^{29}$ On the latter see the early work by Giorgio Agamben, Man Without Content, especially chapters 6-9 (Stanford, Stanford University Press, 1997). 
These five advantages are therefore not the 'advantages' of design per se, or of design in the modern professional sense. They are the advantages of design thought in its extended purview, design as a generalized mode of acting in the world not merely a relatively professional activity, design as a mode of acting in the world in terms of the world as we are now encountering it, i.e., as a world defined-though Latour does not say this-by the coming to presence if not dominance, of the artificial. So implicitly these are historically the advantages of design for the future-in extremis, the advantages of design for what the condition of making need to be in this century. "Need" here meaning to counter 'de-futuring.' "Design" in this form is therefore one answer to the question: What forms must acting take to become adequate to the conditions that are now emerging?

Lukács once described form as that which is simultaneously aesthetic and social. In Latour's formulation "design" is that which is simultaneously design in the both limited sense that we know it (and appraise it historically) and in the extended sense as a mode of acting in the world. That is why, despite the problems and weaknesses immediately apparent on reading them, ${ }^{30}$ these 'five advantages of the concept of "design" ' nonetheless have acute value for this project. They begin to show how it is that design can supply a model, or models, for acting in regard to the conditions that are now emerging; but at the same time these are also, in their own way, descriptions, however inadequate or tentative, of the work of design down to the level of the artefact-and thus also models to set historical inquiry in progress in terms of opening up the nature and character, and above all the work, ${ }^{31}$ of design things.

1. Humility, or modesty. The ability (perhaps) to be less hubristic than technology or making per se is the first advantage or virtue of design noted by Latour. 'It seems to me that to say that you plan to design something does not carry the same risk of hubris as saying that one is going to build something.' The immediate problems with this formulation (architecture is its unfortunate its refutation) should not disguise the more fundamental insight. Latour is here making a virtue of what he called earlier the 'weakness' of design. Whereas modernism could only think in terms of the wholesale break with what was in order to bring what could-be into being (and hence could only think in terms of wholesale transformation-design or revolution indeed!) the situation of designing today is infinitely more complex-and, as Latour points out, paradoxical. For the idea of the modesty of designing as one of the essential characteristics or virtues of acting (well) in the world today, arrives 'just at the moment where the dimensions of the

\footnotetext{
${ }^{30}$ I say 'problems and weaknesses' but as I note below Latour, essentially a social philosopher of Science, has to be congratulated on attempting to think design. The sneering response that I know some made to this paper is wholly unwarranted. In the context of the wholly limited atmosphere, and what we might call the 'scope,' of the study of design Latour's deceptively simple points radically open thought-if nothing else as a challenge to what is called thinking in design to think itself more adequately and in the context of what is now emerging.

${ }^{31}$ This term, which cannot possibly be rendered by "use" or "function" or any of the other reductive alibi's that have been used to dismiss how things act, is central to the question of history, as to the question of design as act and capability. To explore the workings of things in, across and through history is surely what the history of design is about.
} 
tasks at hand have been fantastically amplified by the various ecological crises.' 'Yet' he goes onto say, 'it is precisely because the tasks have increased in scale and impact that we require a 'non- or post- Promethean sense of what it means to act.' The reason for this is that what we need to engage with is now at such scale (the re-design of how we stand to climatic systems) and its implications are so huge, this act must be taken with considerable care and thus with requisite modesty.

What is most radical and most extreme as a task must be undertaken with a certain delicacy, even while it is also the most radical project we (as humans) have ever attempted. That this model of action is, in Latour's terms, 'taking over' public consciousness, may therefore be an essential development, for it points to what now must be now engaged with. Humility, or modesty, is therefore the force of designing-acting in this mode. This force is quite different to that manifest in modern notions of will. Whereas nihilism is the outcome of the latter, 'humility' in this particular sense is its opposite, not action but the resolute ability to act with determination but with care.

2. 'Attentiveness to details'-or what we can call the craft moment in design ['the sense of skillfulness, craftsmanship and obsessive attention to detail'] is the second advantage that Latour sees in design. It stands, in effect, for the "slowing" action of design. Latour's point is that design thought from the emphasis, indeed 'obsession,' of design with detail, craft, and skill runs counter to the modern (ist) urge to revolutionary transformations ('We will) in which questions of detail, or the concrete, are eschewed (Latour: 'it was unthinkable to connect these [craft] features of design with the revolutionary and modernizing features of the recent past'). While, historically, we can again think almost instantly of counter-examples ${ }^{32}$ Latour's point, echoing what he began to chart above, is that it is precisely this "slowing" of design (thought in its craft-like perspective) that is consonant with the current 'modification' in how we conceive of making, where things are no longer as he puts it, "'made" or "fabricated"' (in the technological sense-in which violence is an internal adjunct) but rather 'carefully,' even 'precautionarily,' designed. This precautionary attitude is apposite in a context where, especially ecologically, we need to think in terms of having to be, or having to do that odd thing, being at once 'radically careful' and 'carefully radical.' Questions of detail, skill, craft-in short care-are not merely metaphors of a mode of acting but exemplary indicators of a particular way of conceiving acting; above all, of one that affirmatively reconciles (models) in its moments, at least hypothetically, the impossible tension between the incommensurable requirements of radical change and care.

3. If the first two advantages of design speak, in effect, to the slowing of technical action, the third advantage or connotation of design Latour sees as meaning, or the requirement of interpretation. This was already mentioned above, but it is worth noting that against the modern emphasis on the mono-functional utilitarian object-product and on the model of designing that saw the bifurcation of "use value" and "exchange value" (of "function" and aesthetics) Latour's formulations emphasize two crucial points: (i) the return of a concept of things (from objects to situations, not necessity to the tangible thing is necessitated)

${ }^{2}$ Take for example the hyper-modernist proposals of Ludwig Hilberseimer in the 1920 . 
as gatherings or 'complex assemblies of contradictory issues'; (ii) the proposition of the absorption, and not merely the masking of a superficial non-relation, of 'matter into meaning'-also hence also of meaning (language, code but also more than this) into matter. "Meaning" is obviously an inadequate term here-it is too modern, too much a production of that split (between technology and language, 'work' and 'interaction') which so exercise thinkers across the C2oth. What is actually being referred to here is the much more concrete process of how knowledge and understanding, at once of persons and situations/contexts and things are embodied into the configuration of things. But as in the previous discussion, one understands the direction of Latour's thought here-as also the link he seeks to make to the older etymological understandings of the word thing around the terms "gathering" and "assembly," a connection that allows us to think much more clearly about the negotiative and synthetic work of design, about the fact that design is preeminently a process of negotiating incommensurable requirements and therefore intrinsically a matter of achieving and making exemplary propositional syntheses concerning 'complex assemblies of contradictory issues.'

4. The fourth advantage of design in the Latourian perspective is the simplest to grasp. It is the contention that to design is always to re-design. Latour sees this as challenging the again modern emphasis on creation ex nihlio. He links this (inadequately in my view in the way he expresses this) to the idea that the sense of something 'slightly superficial in design ... something relative' preserves something in design that allows it to act as the other 'to founding, colonizing establishing, or breaking with the past. It is an antidote to hubris and to the search for absolute certainty, absolute beginnings, radical departures.' Affirmatively, we could say that design from this perspective is in essence propositional: that re-design always takes a form (which can be expressed typographically but not verbally) "This!?"-meaning that it combines both an assertion and a question; that it is, and that it asks.

5. The fifth and final advantage of design in Latour's matrix is the one to what I gave the most focus above so I will not re-iterate the point. It is that today designing 'necessarily involves the ethical dimension.' Latour links this, again inadequately, but yet tellingly in terms of the direction in which he takes it, to questions of "good" and "bad." He says to questions of 'good and bad design,' but of course the real issue opened here is good and bad per se; specifically, what is the notion of the good in a world made over as artificial? And how does design engage with the notion of the good? (Just as of course it also engages with the "bad": design has after all a history of serving evil-dramatically in the case of Fascism; ${ }^{33}$ insidiously, but on occasion with scarcely less wickedness, as Victor Papanek reminded us 40 years ago, 34 in terms of the orthodoxies of the profession).

\footnotetext{
${ }^{33}$ A starting point for those interested in this topic is John Heskett, 'Design in Inter-war Germany,' in Designing Modernity: The Arts of Reform and Persuasion, published by Thames \& Hudson and the Wolfsonian Foundation, London and New York, 1995. In more depth Auschwitz, by Deborah Dwork and Robert Jan van der Pelt, New York, Norton, 1996. Thought in relation to ethics: Gillian Rose, Mourning Becomes the Law (Cambridge, University of Cambridge, 1996).

${ }^{34}$ In the splendid rhetoric of the introduction to Design for the Real World (orig. 1971) (Chicago, Academy 
Nonetheless, the key point is made. No action that is as bound into life as design necessarily is can be thought adequately outside an ethical perspective. Design entails propositions concerning the good. There is no design outside its exploration-even when the work intentionally turns its back on this thought. Equally, no activity that is also at the same moment as bound up with power and interests as design can be thought outside of politics and interests (which does not mean it is a merely a kind of sub-section of these). Design, which naturally extends ethics into politics, does so from the stance of the universal (all design is ultimately addressed to all), of possibility (within and of the situation) and of gauging (designing is a gauging of the conditions of living translated into forms that reflect (embody, enact, exemplify, embellish) that gauging. Crucial here also is that design, as an instantiating of ethics and politics is capable of extending the notions of both beyond the limits we assign them-the proviso of which is that we are in turn capable of interpreting what is enacted. ${ }^{35}$

Now, I have presented these five moments of Latour's argument ${ }^{36}$, not because I agree with them $100 \%$, or because I think them in any sense definitive in terms of the 'advantages' of design-on the contrary I do not-but because Latour, again naively but at the same time bravely, does what few in design have yet dared to do, which is lay out design not simply as "design" but as a mode of acting in the world.

To be sure, as you will have felt on hearing this and certainly on reading his text, there are some gaps in the formulation, above all explanatory. There is the absence in Latour's account of any indication as to why, historically, this change in our collective mode of acting is objectively developing such that conditions emerge which both call for (demand) and enable something close to designing (in the expanded sense) to emerge as a necessary-and formative-mode of action in such a world.

I am not, however, going to deal directly with this question here. I have done so in some forthcoming papers and in a work in progress. ${ }^{37}$. While understanding this development is in my view crucial-for we then understand the historical depth of what is being touched upon here-l'd like here to take this as read, and in the time I have left, to focus on the ways in which, despite the weaknesses all too visible in Latour's account, his model nonetheless offers us the beginning of a model of designing that is productive for thinking design at once in terms of the emerging present-future and the past.

What I am suggesting to you is that we have here a kind of incipient model of an ethical history of design capable, as history, of addressing the future.

\footnotetext{
${ }^{35}$ Latour: 'If the whole fabric of our earthly existence has to be redesigned in excruciating details; if for each detail the question of good and bad has to be raised; if every aspect has become a disputed matter of concern and can no longer be stabilized as an indisputable matter of fact; then we are obviously entering into a completely new political territory.'

${ }^{36}$ I have left to one side some of the propositions found in the final third of Latour's paper, that deals with the philosophy of Peter Sloterdijk and the insights the latter might offer for design.

${ }^{37}$ In the essays in the jointly authored book referred to above and in the chapter "'Why the Artificial May Yet Save Us," in Design as Future-Making, ed. Susan Yelavich \& Barbara Adams (London, Bloomsbury, Fall 2014)
} 
What is the basis for this claim? It is two-fold, at once objective and subjective. From a design perspective, what Latour describes with an eye to the future can also be read, without contradiction, into the work of the past. The virtues that Latour describesrespectively, from his five points, now using simply the keywords: 'modesty,' 'craft or details,' 'meaning,' 're-design,' and 'the ethical or matters of concern'-are by no means confined to what is emergent.

As I spoke, historical examples will have immediately come at you. The virtues of modesty; the sense of human import in detail as the attention to the resonance and reciprocity of things; the implication of knowledge (meaning) in matter (with the converse understanding that designed things embodying knowledge are themselves objects of and for understanding); transformative instances of re-design; the ethical implications of making and its attunement ... all those and more are materially instanced in the past, and are instanced so both as moments within what we might call the internal relations of design-everything that is for me encompassed by and in the configurative act of designing, and the external relations, or the wider compass of and action of designed things as they operate and act within the wider frames of social relations, above all as negotiations between material human needs and the forms in which those needs are taken up and met.

All these can be read-which means they can be recovered-from the work of the past. Moreover, it is in and through their recovery in the work of the past that the relatively crude model that Latour presents (necessarily over-simple given the scope of his talk) can-and one predicts, in the immediate will-be augmented, extended, developed and improved. Latour's model prompts the analysis of historical phenomena, but it what it prompts is not simply the investigation of the past on its (the models) terms but the reconstruction (if necessary) of this model as the evidence embodied in the past modifies it.

But, note that what then also occurs, methodologically speaking.

As history or historical work works and re-works (something-like) Latour's model so it works and re-works the theory of design as a whole-at least along the dimensions in which we can think it as a mode of acting in the world (arguably, for the future, its most important dimension). This means the divide that has accompanied virtually the entire trajectory of the modern study of design between "history" on one side and "theory" or "research" on the other is here, at least in principle, overcome.

History is here not the recounting of the "story" of that which is already known in all its essentials (a history for which nothing essentially remains to be discovered-the central critique that can be mounted against all scholastic history) but the investigation of what design has been, might be understood to be, and might be thought again in these terms in the future. Since possibilities are of the essence of what design is about, then we might say that this is doubly consonant: history is the investigation of the possibilities of design(ing) in the context of the exploration of the possibilities of design as itself the exploration of possibility. I emphasize this circularity because this seems to be to be virtuous, to set in chain modes of thinking that break us from the history/theory divide and which conversely use both as the check or the test of the other. ${ }^{38}$

All this is not, note, to seek a return to a singular notion of design as a trans- 
On the contrary, in this process, historical difference is here both preserved and thought. What occurs, however, and this is crucial, is at once the relativization of the norms of designing in the industrial epoch, and an opening to visibility of all that, in the actions and processes of design, its capabilities and aspirations, was rendered conceptually invisible in that period.

To see design as a mode of action in the world is to see it in its true context of operation.

To look at the past in these terms is then also to begin to open up the density of what occurred within and beneath the often suffocating layers of professional ideologies that at one and the same time materially and economically enabled and called forth design, and limited it, above all in thought and in how design came to consciousness. But it is also, and this is crucial, the way we think design back into history (and thus also our future). 39

Here we can come back, once again, to the injunction with which I began: 'The task to be accomplished is not the conservation of the past, but the redemption of the hopes contained in it.'

The hopes contained in the past are the hopes of a world hospitable to all (to all species I will add, for our human hope is that we do not purchase our conditions of existence at the expense of those of other species-on which, not so ultimately, we are dependent). What Latour embryonically posits is the beginning of the way in which human hopes for a humane hospitable world-hopes that cannot be divorced from the human project of what Herbert Simon called, 'the search for good designs'40 — can be organically linked to design in the more limited sense, not as an abstract value, or the act of 're-looking,'41 but as capacity or as a series of capacities.

\footnotetext{
${ }^{38}$ This circularity works equally from the side of theory (or methodology, it comes to much the same thing). The idea that theory-or today "research" since the latter dares scarcely to use the former termshould be conducted in the absence of historical perspective is, I hope, already discredited. Here the "futurological" model that Latour embryonically constructs adds in the dimension of time without which no model of designing, in its capabilities or attributes, can be adequately secured.

39 Latour: 'Critique, deconstruction and iconoclasm, once again, will simply not do the job of finding an alternative design. What is needed instead are tools that capture what have always been the hidden practices of modernist innovations: objects have always been projects; matters of fact have always been matters of concern.'

${ }^{40}$ Herbert Simon, The Sciences of the Artificial (Cambridge, MIT press, 2001) p. 164. I take Simon's proposition to indicate the search for the manners and modes-the forms-of meeting material and immaterial human needs, well. On the search for these, and the politics of so doing, see the essay by Stephen Yeo, Stephen Yeo, 'State and anti-state: Reflections on social forms and struggles from 1850' in Philip Corrigan (ed.) Capitalism, State Formation and Marxist Theory (London, Quartet, 1980) p. 115. ${ }^{41}$ We tend to forget that while we tend to read the act of "re-looking" as merely the act of giving a "new and better "look" or shape to something' such re-looking may not be as banal as sometimes thought. We should be cognizant first of all of the manner in which we use the term to 'give' a look to something (what, then is the gift here? Is it negligible or significant?). Second of all we should pay more attention to Heidegger's little formulation regarding world views and things: that the former gives to things their look and men their outlook-which means also of course that this 'outlook,' to be operative in the world, cannot but be encapsulated in the form, which is to say in part the look, of things. Looking is less
} 
Between Herbert Simon's extraordinary and never sufficiently thought postulate; the nature of the work achieved through the act of designing; and through something like Latour's model, we now have the embryo, at last, of a set of concepts, categories and actualities that can begin to allow us to move back and forth between the human in the wide sense, and the more focused, the necessarily narrower, concerns of design-and can do so in ways that do not end up postulating either of the mantra's that are so often taken up at this point; that "everything we do is design" or (that which ironically comes to the same thing) that design is nothing-but a narrow professional concern.

In so far as both of these empty design, the wager of the act of thinking design historically in the manner outlined here is that at last we begin to fill the content of design.

\section{Part III}

Yet in sketching all this all this I am painfully aware of the degree of abstraction I have brought to the problem. One excuse is that this essay is the corollary of the (extreme?) empiricism that characterizes-if unsurprisingly-the history of design. Another is that its implications are not all necessarily abstract. On the contrary, the point in view not to a history of facts and a theory (or a research) of abstractions, but their opposites, a history that builds out of the analysis-the detailed analysis I insist-of material, actual things; of design configurations, in their materiality if you like. But again, in what context one asks? And one receives the answer: from the context of history.

Here let me put in place a quote that the art historian T. J. Clark used to some effect back in 1974, when he wrote a short but seminal essay on the social history of art entitled the 'The Conditions of Artistic Creation.'42 The quotation comes from Georg Lukács, from 1922, from the essay "Reification and the Consciousness of the Proletariat":

innocent than we often wish it to be. Equally of course, in many commodities, we may think there is less than meets the eye; but then every commodity unavoidably contains the outlook of the entirety of capitalism. 
'And yet, as the really important historians of the nineteenth century such as Riegl, Dilthey and Dvorak could not fail to notice, the essence of history lies precisely in the changes undergone by those structural forms which are the focal points of man's interaction with environment at any given moment and which determine the objective nature of both his inner and outer life. But this only becomes objectively possible (and hence can only be adequately comprehended) when the individuality, the uniqueness of an epoch or a historical figure, etc., is grounded in character of these structural forms, when it is discovered and exhibited in them and through them.' 43

Clark was seized by this quotation because two of three historians that Lukács namesRiegl and Dvorak-were art historians. 44 "What an age this was' says Clark, 'when Riegl, and Dvorak were the real historians, worrying away at the fundamental questions - the conditions of consciousness, the nature of 'representation.' And he continues:

'the roll-call of names - Warburg, Wolfflin, Panofsky, Schlosser - is not what matters exactly. It is more the sense we have, reading the best art history of this period, of an agreement between protagonists as to what the important, unavoidable questions are. It is the way in which the most detailed research, the most arcane discoveries, lead back time and again towards the terrain of disagreement about the whole nature of artistic production. What are the conditions of artistic creation? (Is that word 'creation' allowable anyway? Should we substitute for it the notions of production or signification?) What are the artist's resources, and what do we mean when we talk of an artist's materials - is it a matter, primarily, of technical resources, or pictorial tradition, or a repertory of ideas and the means to give them form? Clearly - the convenient answer, which has become the common wisdom now - it is all three: but is there a hierarchy among them, do some 'materials' determine the use of others? Is that hierarchy fixed?'

Clark's invocation of "questions" as the basis of inquiry - the only basis on which inquiry stays alive - is still powerful: a continuing riposte to false scholasticism. Yet it is notable that however much he plays off Lukács' quote in his essay he gives almost no attention to the substantive part of the quotation-the part that must have jumped out, I think, at everyone here. The half-sentence 'The essence of history lies precisely in the changes undergone by those structural forms which are the focal points of man's interaction with environment at any given moment and which determine the objective nature of both his inner and outer life,' after all describes exactly the subject matter of the history of design.

Design is after all the act of configuring 'the structural forms which are the focal points of man's interaction with environment at any given moment.' And it does so in a particular manner. The reason why such structural forms 'determine the objective nature of both [man's] inner and outer life'-laying equal stress here on the 'inner' as well

\footnotetext{
43 Lukács, History and Class Consciousness, ibid, p. 153

${ }^{44}$ Though significantly Riegl especially, but also in Dvorak (who was Riegl's student) were at least in part historians of what was then called applied art.
} 
as outer-is that what designed configuration achieves is precisely the achievement of a relation-an affirmative relation we must insist-between the inner and outer, or between, to use a more general language, subject and object (except these terms are endlessly reductive in comparison to 'inner' and 'outer').

So important is this work that we need in fact to slightly re-phrase Lukács sentence: 'The essence of history lies precisely in the changes undergone by those structural forms which are the focal points of man's interaction with environment at any given moment and which determine the objective and subjective nature of both his inner and outer life.'

In fact, we can go one stage further and say that the entire point of designalmost, I would say its essence-is that it achieves this most difficult of (non-) relations. If design is the ability (as I believe it is) to deal with incommensurable requirements the incommensurability most contentious, most difficult to resolve, especially in the modern world, is that between object and subject. Historically, as it manifests itself within the industrial product, design is after all called into being to deal with this split. We can say that, through the forms of modern design, design deals with this split in the form economy wishes-that is it re-unites 'use value' (or technology) with exchange-value (or desire) 45 and does so in so frictionless a manner that, erased at the level of our encounter with things, the original split is seemingly paradoxically all the more preserved in its operative underlying social force.

Let us make no mistake here. The subject-object split is perhaps the central distinction from which the entirety of the modern period and its economic and social relations flows. What begins, at least philosophically, with Descartes rapidly becomes, as representation, the formative operative means of distinguishing, and thus valuing, both 'subject' (he who represents, and my use of the male pronoun is deliberate) and 'object'all that is not a subject and whose measure, as Heidegger pointed out in probably the best single essay we have on this process, ${ }^{46}$ is given by the subject (for objects in tis view possesses not intrinsic ability to name and give measure to themselves-they are named, as precisely, slaves and servants were named.

To say this is to give immediately a suggestion why, of all arenas within design, looking at the manner in which design "resolves" this split in practice is the moment where we are also looking at the most acute intersection of the design configurative act, in the tight sense of this work, and wider social relations. It is to look at how design may both-and in the same moment-serve this effacing of this split and instantiate in that effacing the material proof of its transcendence or overcoming.

The material way in which design "solves" this problem should not be discounted. For example, Adorno, in Negative Dialectics (1966) his last and deepest philosophical work, struggles with and gives considerable attention to this problem. The

45 This is far too simple of course. Yet in a crude way it gets at what is involved here. For a more complex reading see especially chapter 10 of Jean Baudrillard, Towards a Critique of the Political Economy of the Sign (St Louis, Telos Press, 1971).

${ }^{46}$ Martin Heidegger, 'The Age of the World Picture" in The Question Concerning Technology and Other Essays (New York, Harper, 1977). 
closest thing to a definitive statement that he comes to is the following: 'Mediation of the object means that it must not be statically dogmatically hypostatized but can be known only as it entwines with subjectivity; mediation of the subject means that without the moment of objectivity it would be literally nil.' To which he adds the significant rider: 'an indication of the objects preponderance is the impotence of the mind-in all its judgments as well as, to this day, in the organization of reality. The negative fact the mind failing in identification, has also failed in reconcilement, that is its supremacy has miscarried, becomes the motor of its disenchantment. ${ }^{47}$

Thought carefully, the first and important sentence of this pair is much less abstract than it seems. Nonetheless, even when we grasp the essential dialectic, we realize immediately a truth: that what Adorno can only posit as a should or as an obligation placed on mind, design enacts in practice - if in the most humble of ways (I am thinking here as I write of my favorite "Good Grips" vegetable peeler that I use an a daily basis) ${ }^{48}$ and does so with apparent ease, the ease which is precisely why design is valued on a purely economic plane (why design was and is essential to commodification) but an ease that is also much less understood, much less thought than it should be. For look carefully at Adorno's second sentence. He is telling us there that thought (a.k.a. the subject) pays a terrible price for the subject-object split. In this split thought thinks it is victorious, that it lords it over everything in the world that is not it: that it, and it alone, can (in Heidegger's words) give 'the measure to all things.' But it turns out, of course, to be not so simple. Adorno's second sentence says exactly this. It says, in effect, that the price the subject pays for this is two-fold. First, the subject who represents, dissociates, that is separates himself from everything that is. This was also Latour's point when he made his savage criticism of 'the modernist' quoted earlier in the talk. But, second, and this is Adorno's crucial point. The domination by the subject of the object is itself illusory. For in the subject-object split the subject does not have all the power. Objectification extracts its price. The subject becomes beholden to the processes of objectification and hence beholden to the object. In this relation the mind (thinking itself as only a 'subject') discovers its lack of power.

This is the meaning of Adorno's sentence, 'an indication of the objects preponderance is the impotence of the mind-in all its judgments as well as, to this day, in the organization of reality. ' Why is mind impotent vis-à-vis the object that it creates?

Because the mind 'failing in identification, has also failed in reconcilement, that is its supremacy has miscarried, becomes the motor of its disenchantment.49 In other words, having created the subject-object split, mind itself (as "subjectivity" in the modernist, dissociated sense) cannot identify with, cannot reconcile itself with, its other-that other on which in truth its is dependent.

47 Theodor Adorno, Negative Dialectics (New York, Continuum, 1973) p. 186.

${ }^{48}$ (http://www.oxo.com/p-223-swivel-peeler.aspx)-

49 Theodor Adorno, Negative Dialectics (New York, Continuum, 1973) p. 186. 
This is our human tragedy. And it is a real tragedy because the crises that will ensue in the next decades, which are likely to cost the lives of millions and cause untold misery on scales infinitely larger even than those of the last century, are a direct result of this failure. It is surely absurd, in the face of this tragedy, to put up my Oxo Good-grips peeler!

It is not. For what can be read on one side as nothing more than a commodity gimmick can be read on the other as a model-tiny but nonetheless real-of precisely the 'identification' and 'reconciling' that Adorno called for.

I am delighted therefore to end this talk with my peeler. It stands for the virtues of design (as a mode of action) liberated from Design (Capitalized, an economic service). Its history, recovered, contains the entire history of the subject-object split, of false and real attempts to overcome that split and of the history to come of that overcoming.

No wonder it is in its form so beautiful! 
